\title{
Dairy cattle prefer shade over sprinklers: Effects on behavior and physiology
}

\author{
K. E. Schütz, ${ }^{* 1}$ A. R. Rogers, ${ }^{*}$ N. R. Cox, ${ }^{*}$ J. R. Webster, ${ }^{*}$ and C. B. Tucker† \\ ${ }^{*}$ AgResearch Ltd, Private Bag 3123, Hamilton 3240, New Zealand \\ †University of California, Department of Animal Science, 1 Shields Ave., Davis 95616
}

\section{ABSTRACT}

Cattle will readily use shade in warm weather, but less is known about voluntary use of sprinklers. We examined preferences of 96 Holstein-Friesian dairy cows (milk yield: $12.7 \pm 3.48 \mathrm{~kg}$ per day; mean $\pm \mathrm{SD}$ ) for sprinklers, shade, or ambient conditions after walking $2.0 \mathrm{~km}$ or $0.3 \mathrm{~km}$ before afternoon milking $(\mathrm{n}=48$ cows/distance). Each cow was individually tested on 3 consecutive days with a different paired choice each day: 1) shade or sprinklers, 2) shade or ambient conditions, 3) sprinklers or ambient conditions. Average air temperature during testing was $22.3^{\circ} \mathrm{C}$. Cows preferred shade over sprinklers ( 62 vs. $38 \% \pm 5.0 \%$; mean $\pm \mathrm{SE}$ ) and shade over ambient conditions (65 vs. $35 \% \pm 5.1 \%$; mean $\pm \mathrm{SE})$. Cows showed no preference between sprinklers and ambient conditions (44\% of the cows chose sprinklers, $\mathrm{SE}=5.3 \%$ ). The preference for shade over sprinklers and ambient conditions increased with air temperature, solar radiation, and wind speed. Walking distance did not influence the preference for any treatment. Respiration rate was decreased most by sprinklers (38\% decrease) but also decreased in shade and ambient conditions (17 and 13\% decrease, respectively; standard error of the difference $=4.7 \%$ ). Similarly, surface temperature was decreased most by sprinklers ( $11.4 \%$ decrease), compared with that by shade $(1.0 \%$ decrease), or that by ambient conditions (1.4\% increase; standard error of the difference $=1.82 \%)$. Furthermore, sprinklers reduced insect avoidance behaviors, including number of tail flicks and hoof stamps. In conclusion, dairy cattle preferred to use shade in summer despite sprinklers being more efficient in decreasing heat load and insect avoidance behavior.

Key words: dairy cattle, heat stress, shade, sprinklers

Received July 8, 2010.

Accepted October 4, 2010.

${ }^{1}$ Corresponding author: karin.schutz@agresearch.co.nz

\section{INTRODUCTION}

Exposure to summer weather affects the behavior and physiology of cattle. Increased heat load, caused by a combination of air temperature, relative humidity, solar radiation, and air movement, increases body temperature and respiration rate, and can reduce feed intake, and milk and meat production (Hahn, 1999; Ominski et al., 2002; West, 2003). Excessive heat load can also negatively affect breeding performance in dairy cattle by reducing fertility (Roman-Ponce et al., 1977; De Rensis and Scaramuzzi, 2003) and can, in extreme cases, result in death (Armstrong, 1994).

Cattle readily use shade when given access to it and the provision of shade can alleviate negative effects of increased heat load (Roman-Ponce et al., 1977; Valtorta et al., 1997). Shade use increases with higher ambient air temperature and solar radiation (Kendall et al., 2006; Tucker et al., 2008). There is evidence that dairy cattle are highly motivated to use shade in warm weather (Schütz et al., 2008) and consider shade a valuable resource that they are willing to compete for (Schütz et al., 2010). Although it is clear that shade is beneficial and seems to be valuable to cattle, cooling with water, with or without fans, is more efficient in reducing heat load than is shade (Seath and Miller, 1948; Mitlöhner et al., 2001; Correa-Calderon et al., 2004). For example, cooling with water reduces respiration rate and body temperature more than shade alone (Igono et al., 1987; Correa-Calderon et al., 2004).

In pastoral systems, the vaginal body temperature of dairy cattle often reaches a peak during and following the afternoon milking (Kendall et al., 2006), in part, because pastured dairy cows often walk considerable distances to the milking parlor (on average, $2 \mathrm{~km}$, on large New Zealand farms; Tucker et al., 2005). The use of shade and sprinklers at the milking parlor in the afternoon can be an effective way to reduce heat load at this time. Exposure to fans or sprinklers or both around the time of milking can reduce body temperature for around $4 \mathrm{~h}$ after milking (Kendall et al., 2007). Therefore, sprinklers may be a practical option for farmers to reduce heat stress; for example, in a survey of New Zealand dairy farms, approximately $40 \%$ of 
the farms used sprinklers at the milking shed (Tucker et al., 2005). There may also be other benefits from sprinkler use; for example, there is anecdotal evidence from farmers that the use of sprinklers reduces fly load, and experimental evidence that sprinklers reduce fly avoidance behaviors (Kendall et al., 2007). However, there is relatively little research examining voluntary use of sprinklers, when water cooling is presented alone, without other resources such as feed or shade. Some have suggested that cattle may find sprinklers aversive (standing with their heads low, Kendall et al., 2007, or avoiding use, Marcillac-Embertson et al., 2009), and that water cooling used on cooler days may result in hypothermia (relative to control animals, Kendall et al., 2007). In contrast, others have documented voluntary use of water cooling by dairy cattle, especially in warm weather $\left(>32^{\circ} \mathrm{C}\right.$, Seath and Miller, $1948 ;>27^{\circ} \mathrm{C}$, Igono et al., 1987) but also at more moderate temperatures $\left(>20^{\circ} \mathrm{C}\right.$; Legrand et al., submitted).

Our objectives were to examine whether dairy cows prefer shade, sprinklers, or no cooling in summer and assess if the preference was influenced by increased heat load, namely with warm weather or increased distance walked. We predicted that sprinklers would be more efficient in reducing the heat load and provide other benefits, such as reduced insect avoidance behaviors. Furthermore, we predicted that cows would, in general, prefer the shade, but that the preference would shift toward sprinklers in warmer weather or after walking a longer distance (2.0 vs. $0.3 \mathrm{~km})$. Finally, we predicted that cows that are possibly more susceptible to heat stress (e.g., have higher body weight, milk production, or those with darker coats), would prefer sprinklers.

\section{MATERIALS AND METHODS}

\section{Animals and Treatments}

The experiment was carried out during February and March 2008 (Southern Hemisphere summer) and all procedures involving animals were approved by the Ruakura Animal Ethics Committee under the New Zealand Animal Welfare Act 1999. Ninety-six Holstein Friesian dairy cows were divided into groups of 3 (32 groups in total) balanced by age (primiparous vs. multiparous) at the AgResearch Number 1 Dairy in Hamilton, New Zealand (latitude $37^{\circ} 47^{\prime} \mathrm{S}$, longitude $\left.175^{\circ} 19^{\prime} \mathrm{E}\right)$. The cows were between 3 and 12 years of age, were $173 \pm 19$ DIM, had BCS of $5.0 \pm 0.77$ (on a scale of 10; Roche et al., 2004), BW of $486 \pm 61 \mathrm{~kg}$, and produced $12.7 \pm 3.48 \mathrm{~kg}$ of milk per day (mean \pm SD; range: $3.3-23.1 \mathrm{~kg}$ of milk per day; recorded during training days). The percentage of black hair was estimated from digital photographs of both sides of each cow using image analysis software (Scion Image v.4.0.2, Scion Corporation, Frederick, MD). Cows had $82 \pm 20 \%$ black coat color (mean $\pm \mathrm{SD}$ ). The cows were milked twice daily (approximately 0700 and $1600 \mathrm{~h}$ ) and were given a fresh sward of pasture after each milking. Grass and maize silage was provided as supplementary feed and water was freely available.

Each cow was individually tested on 3 consecutive days with a different paired choice per day in a balanced crossover design: 1) shade or sprinklers, 2) shade or ambient conditions, and 3) sprinklers or ambient conditions. All testing was carried out between 1230 and $1600 \mathrm{~h}$. Each group of 3 animals was tested simultaneously in separate testing areas; thus, all treatment combinations were tested at a given time (Figure 1). The location (left or right) of the treatments was alternated between groups. The treatments, one in each arm of the test arena (Figure 1), consisted of wooden structures ( $2.3 \mathrm{~m}$ high, $4.0 \mathrm{~m}$ long, $3.0 \mathrm{~m}$ wide) mounted with either shade cloth blocking $99 \%$ of solar radiation (Donaghys Industries Ltd., Christchurch, New Zealand), sprinklers $(5 \times 1.5$-mm Neta full circle micro sprinkler, PPI Corporation Pty Ltd, Australia; see Figure 1 for placement) or no cooling (ambient conditions, wooden structure only). The average water flow from the sprinklers was $178 \mathrm{~mL} / \mathrm{m}^{2}$ per min. To provide animals with a visual cue for each treatment, the legs of the structures had a 1-m section covered in colored cloth (green, red, or yellow) at 1 to $2 \mathrm{~m}$ from the ground. The colors allocated to the different treatments were balanced between groups to avoid any color preferences. Thus, each animal always had the treatments in the same location and with the same color cues. All structures had a rectangle perimeter of $3 \times 4 \mathrm{~m}$ of white paint directly beneath the structure to facilitate behavioral observations. The grass in the entire testing arena was mown to minimize grazing.

To examine the effect of walking distance on the preference, half of the animals (16 groups) walked either $0.3 \mathrm{~km}(0.33 \pm 0.31 \mathrm{~km}$, mean $\pm \mathrm{SD})$ or $2.0 \mathrm{~km}(2.02$ $\pm 0.30 \mathrm{~km}$, mean $\pm \mathrm{SD}$ ) before testing on a level farm track (packed soft rock with sand cap) leading from the paddock to the test arena. The duration of the walk was 6:55 \pm 1:28 $\mathrm{min}$ and 36:00 \pm 7:41 $\mathrm{min}$ for 0.3 and $2.0 \mathrm{~km}$, respectively (mean $\pm \mathrm{SD}$ ). Four groups of 3 animals (2 walking $0.3 \mathrm{~km}$ and $2.0 \mathrm{~km}$, respectively) were tested per day; therefore, all 32 groups were tested during a total of $40 \mathrm{~d}$ (4 groups during $3 \mathrm{~d}$ of testing; 2 d of previous exposure, described below).

Four groups were tested consecutively each day (2 of each walking distance, alternating the start order of the walking distance between days) but each cow was only tested once per day. Immediately after walking the required distance, the group to be tested was held 


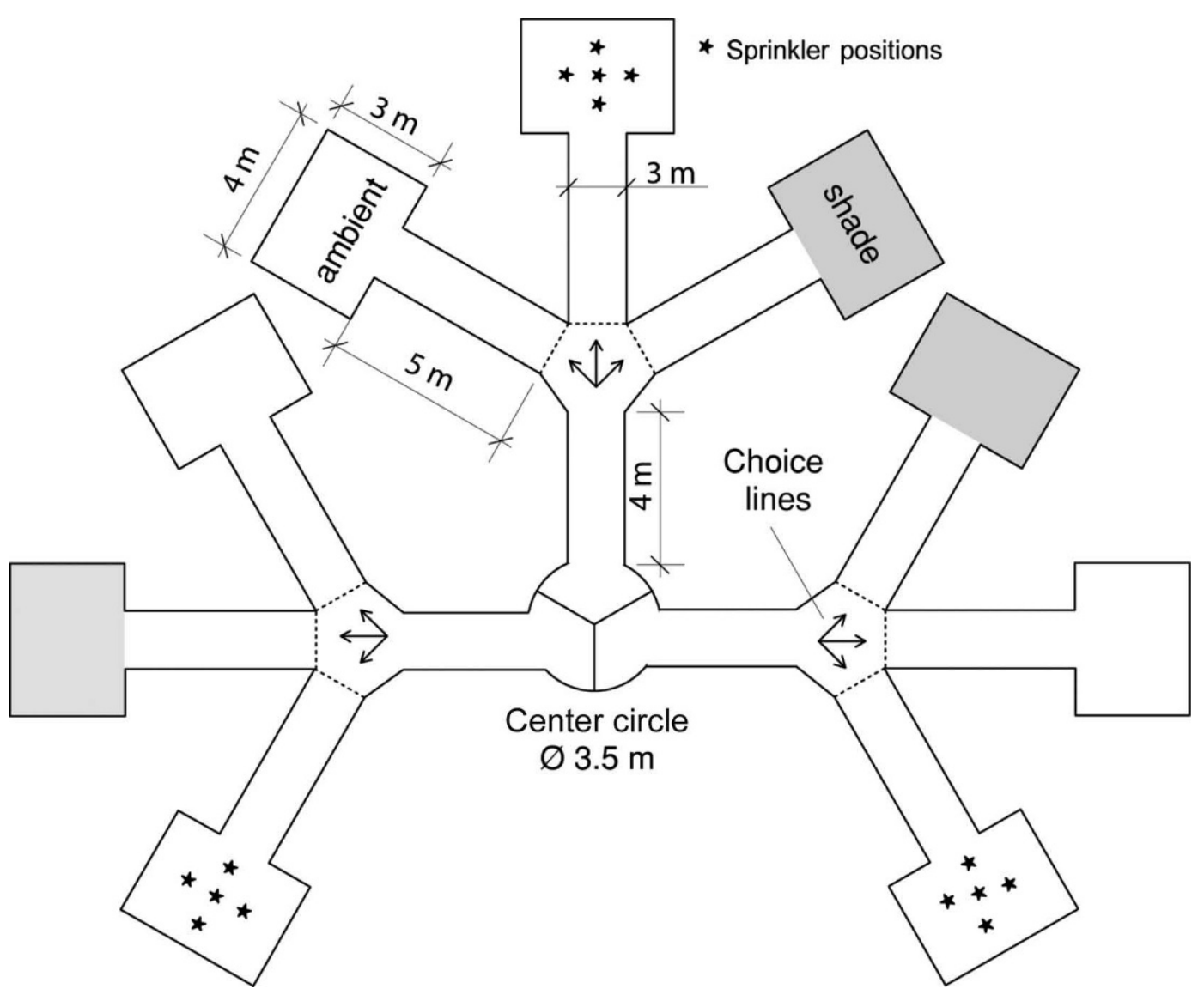

Figure 1. The test arena used in the preference test.

in a central circular area segmented into 3 sections (1 cow/section, Figure 1) for a maximum of 2 min, during which surface temperature and respiration rate (see below) were recorded. Animals were then given access to a single treatment combination. Order of exposure to treatment combinations were balanced within groups and across time. Once a choice had been made by crossing a painted line (Figure 1) with both front hooves, the exit was blocked to prevent the animal from walking back; therefore, once the choice was made, the cow had to remain in the chosen resource. Behavioral measurements, including insect avoidance behaviors and head position were recorded for $10 \mathrm{~min}$. Animals were then returned to the central area where surface temperature and respiration rate were recorded a second time. The group was then walked to a holding paddock adjacent to the milking parlor until all 4 groups had been tested. At this point, they were taken to afternoon milking and then grazed overnight as a single group of 12 animals.

All animals were exposed to the test arena and procedures $2 \mathrm{~d}$ before testing. During the first day of exposure, the cows were introduced to the test arena and all 3 treatments. The cows were allowed to explore the entire arena and all treatments. This was repeated 3 times on the first day and the time in each treatment ranged between 2 and $8 \mathrm{~min} / \mathrm{d}$. On the second day of exposure to the experimental setup, the cows were given access to 2 out of the 3 treatments. This was repeated 2 times such that each cow experienced all 3 pairwise treatment options. This procedure was repeated again on the second day. During training and testing, the groups of 3 cows grazed separately in their respective groups. In addition to this short-term exposure, all animals had extensive, voluntary experience with shade from trees on the farm. All cows also had previous experience with involuntary use of sprinklers as part of normal procedure during milking on warm days.

\section{Behavioral Measurements}

The treatment choice was recorded for each cow. Within each treatment, head position and insect avoidance behaviors were recorded. Head position was defined as high (top of the poll level with or above the withers), low (chin level with or below the brisket), or medium 
(between low and high) and was measured with instantaneous scan sampling (Martin and Bateson, 1993) every minute during the 10 min of testing (11 recordings per cow). Furthermore, the location of the poll, inside or outside (level with or outside) the painted rectangle beneath the structure, was also recorded. Multiple observers were used for data collection. Inter-observer reliability for the scan observations, as measured by percentage agreement, was between 79 and $100 \%$ for all behaviors. Inter-observer agreement was lowest when assessing the head position for low, medium, or high.

Insect avoidance behaviors were recorded continuously during the 10 min that the animal was in the chosen treatment. One person observed each cow and counted the number of tail flicks, hoof stamps, skin twitches, and head throws for $30 \mathrm{~s} /$ behavior. Once the observers completed one 30-s period/behavior, they began the process again and generated approximately $2.5 \mathrm{~min}$ of observation/behavior during the 10-min test period. A tail flick was defined as the tail crossing the midline of either rear leg in an outwards and upwards motion. A hoof stamp was defined as lifting one hoof entirely off the ground and putting it down in approximately the same location, within 1 to 2 hoof lengths. A skin twitch was defined as a defined, repeated movement of skin on a point on the cow's shoulder, midway between the top of the front leg and the withers. A definite cease of movement at the shoulder was required before counting the next twitch. A head throw was defined as a rapid head movement touching any part of the body. The head needed to return to a neutral position (head facing forward) before counting the next head throw. Multiple observers were used for data collection. The inter-observer reliability for the continuous recordings, as measured by correlation, was between 0.84 and 0.97 for all behaviors. Inter-observer agreement was lowest when assessing skin twitches.

\section{Physiological Measurements}

Respiration rate was recorded for each cow immediately before and after walking either 0.3 or $2.0 \mathrm{~km}$ and after $10 \mathrm{~min}$ in the chosen treatment. The animal was video recorded for $1 \mathrm{~min}$ using a Sony Digital Handycam (DCR-TRV355E PAL with a $700 \times$ digital zoom, Sony, Japan) while it was standing still. Respiration rate (number of rises of the flank/30 s) was analyzed from these video recordings. Respiration rate is expressed as the number of breaths/min to facilitate comparisons with other studies. Due to animals moving, it was not possible to obtain respiration rate for 30 , 36 , and $35 \%$ of the observations from before and after the walk, and after $10 \mathrm{~min}$ in the chosen treatment, respectively. Inter-observer reliability, as measured by correlation, was 0.97 .

Core body temperature was recorded every minute using a modified vaginal controlled internal drug release insert (CIDR, InterAg, Hamilton, New Zealand) fitted with a microprocessor-controlled Minilog-TX data logger (accuracy: $\pm 0.3^{\circ} \mathrm{C}$, resolution: $0.2^{\circ} \mathrm{C}$; Vemco Ltd, Shad Bay, Nova Scotia, Canada). Temperature loggers were inserted into the vaginal cavity on the morning of the first day of training and removed on the last day of testing, $5 \mathrm{~d}$ in total per cow. Skin temperature was recorded using a hand-held infrared (IR) thermometer (accuracy: $\pm 1{ }^{\circ} \mathrm{C}$, resolution: $0.1^{\circ} \mathrm{C}$; Mikron IR Man, model MI-N-14+, Mikron Infrared Inc., Oakland, NJ). Recordings were taken immediately on arrival in the testing arena and after $10 \mathrm{~min}$ in the chosen treatment. The IR thermometer was held approximately 1 to $2 \mathrm{~m}$ from the animal at a midpoint between the top of the front leg and the withers. The coat color at the point of measurement was recorded (black or white). Thirty-two percent of the data was not used in the analysis due to missed recordings, or different coat color points (one black and one white) for each individual cow. Daily milk production was recorded individually for all animals.

\section{Environmental Measurements}

Weather measurements (ambient air temperature, relative humidity, wind speed, rainfall, solar radiation, and black globe temperature, $\boldsymbol{B} \boldsymbol{G} \boldsymbol{T})$ were recorded and the temperature-humidity index (THI; Igono et al., 1992) and heat load index (HLI; Gaughan et al., 2008) were calculated at 10-min intervals during the $24 \mathrm{~d}$ of testing as follows:

$$
\begin{gathered}
T H I=(1.8 \times T+32)-[(0.55-0.0055 \times R H) \\
\times(1.8 \times T-26)] \text { and } \\
H L I=\operatorname{IF}[B G T>25,8.62+(0.38 \times R H) \\
+(1.55 \times B G T)+\exp (-W S+2.4)-0.5 \times W S, \\
10.66+(0.28 \times R H)+(1.3 \times B G T)-W S],
\end{gathered}
$$

where $T=$ air temperature $\left({ }^{\circ} \mathrm{C}\right), R H=$ relative humidity $(\%), B G T=$ black globe temperature $\left({ }^{\circ} \mathrm{C}\right)$, and $W S$ $=$ wind speed $(\mathrm{m} / \mathrm{s})$.

All weather measurements were taken in a field near the testing arena (approximately $100 \mathrm{~m}$ away). The microclimate (air temperature, $B G T$, and relative humidity) in the shade, sprinkler, and ambient treatments was recorded at 1-min intervals during testing with HOBO Pro Dataloggers (Onset Computer Corporation, 
Table 1. Summary of meteorological records for the $24 \mathrm{~d}$ of testing in summer, including the microclimate in the treatment choices

\begin{tabular}{|c|c|c|c|c|c|c|c|c|c|c|}
\hline \multirow[b]{2}{*}{ Weather variable } & \multicolumn{2}{|c|}{1000 to $1600 \mathrm{~h}$} & \multicolumn{2}{|c|}{$24 \mathrm{~h}$} & \multicolumn{2}{|c|}{$\begin{array}{c}\text { Sprinklers } \\
(1230 \text { to } 1600 \mathrm{~h})\end{array}$} & \multicolumn{2}{|c|}{$\begin{array}{c}\text { Shade } \\
(1230 \text { to } 1600 \mathrm{~h})\end{array}$} & \multicolumn{2}{|c|}{$\begin{array}{c}\text { Ambient } \\
(1230 \text { to } 1600 \mathrm{~h})\end{array}$} \\
\hline & Mean & Range & Mean & Range & Mean & Range & Mean & Range & Mean & Range \\
\hline Black globe temperature $\left({ }^{\circ} \mathrm{C}\right)$ & 30 & $18-38$ & 21 & $6-43$ & 23 & $17-42$ & 26 & $24-32$ & 29 & $18-43$ \\
\hline Relative humidity (\%) & 50 & $25-79$ & 65 & $24-91$ & 83 & $26-100$ & 49 & $18-88$ & 42 & $13-100$ \\
\hline Solar radiation $\left(\mathrm{W} / \mathrm{m}^{2}\right)$ & 542 & $52-1,147$ & 230 & $0-1,147$ & - & - & - & - & - & - \\
\hline Temperature-humidity index & 68 & $59-74$ & 63 & $46-74$ & 70 & $64-94$ & 71 & $66-76$ & 73 & $63-83$ \\
\hline Heat load index & 74 & $46-97$ & 61 & 33-102 & - & - & - & - & - & - \\
\hline
\end{tabular}

Bourne, MA) and the THI was calculated. The water temperature from the sprinklers was also measured 3 times/d, during an 8-d subset of the $24 \mathrm{~d}$ of data collection. On average, the sprinkler water temperature was $23.6 \pm 1.8^{\circ} \mathrm{C}($ mean $\pm \mathrm{SD})$.

\section{Statistical Analysis}

Individual cows served as the experimental units. Behaviors considered in the statistical analysis included treatment choice, tail flicks, hoof stamps, head throws, skin twitches, and head (low, medium, high) and poll (inside or outside the painted rectangle) position. Physiological variables considered in the statistical analysis were respiration rate and body temperature (mean values from before and after the walk, and after the 10min test period), surface temperature (before and after the 10-min test period), and milk production during the 2 training days. Normality and homoscedasticity of the residuals were examined for all variables. All variables were analyzed without transformation except for tail flicks, hoof stamps, head throws, and skin twitches when square root transformation was used. A generalized linear model with binomial distribution and logit link was used to analyze the choice data separately for each pair of treatments. A residual maximum likelihood (REML) model with random terms for the 8 wk and 3 animals in each group, and fixed terms for the walking distance, choice factors, and explanatory variables (\% black coat color, initial body weight, condition score, milk production) was used to analyze the physiological variables and the insect avoidance behavior measurements. Finally, a generalized linear mixed model, with the same structure as the REML model but with binomial distribution and logit link, was used to analyze the head and poll position data (proportional data).

The weather information (air temperature, solar radiation, THI, and $H L I$ ) was averaged for each day $(1000$ to $1600 \mathrm{~h})$. We examined the effect of weather on the relationship between the behavioral and physiologi- cal variables and the walking distance using the same models (REML, generalized linear model, and generalized linear mixed model) as above.

The effect of coat color was also explored. The difference in surface temperature between black and white coat color after the walk and after the time in the treatment was analyzed using REML and the same model as described above (except for using black or white coat color instead of percentage of black coat color). All statistical analyses were conducted using the statistical package GenStat, version 10.2 (VSN International, Hemel Hempstead, UK).

\section{RESULTS}

\section{Environmental Conditions}

Air temperature, $B G T$, wind speed, rain fall, humidity, solar radiation, and calculated $T H I$ and $H L I$ values are summarized in Table 1, as well as the microclimate (air temperature, humidity, $B G T$, and calculated $T H I$ ) in the 3 treatments.

\section{Effect of Walking Distance on Heat Load}

Before the walk, when the cows were at pasture, no differences existed in respiration rate or body temperature between the groups walking the 2 distances; respiration rate and body temperature were 55.4 vs. 53.8 breaths/min (standard error of the difference, SED: 3.17 breaths $/ \mathrm{min}, P=0.623$ ) and 38.6 vs. $38.5^{\circ} \mathrm{C}$ (SED: $0.06^{\circ} \mathrm{C}, P=0.190$ ) for $0.3 \mathrm{~km}$ and $2.0 \mathrm{~km}$, respectively. Both respiration rate $(P<0.001)$ and body temperature $(P<0.001)$ were higher in warm weather, as measured with higher $H L I$, before the walk in both groups.

The increase in respiration rate was greater in cows that walked $2.0 \mathrm{~km}$ compared with those that walked $0.3 \mathrm{~km}(31.8$ and $8.3 \%$ increase for the $2.0 \mathrm{~km}$ and $0.3 \mathrm{~km}$ walk, respectively; SED: $5.50 \%, P<0.001$ ). 


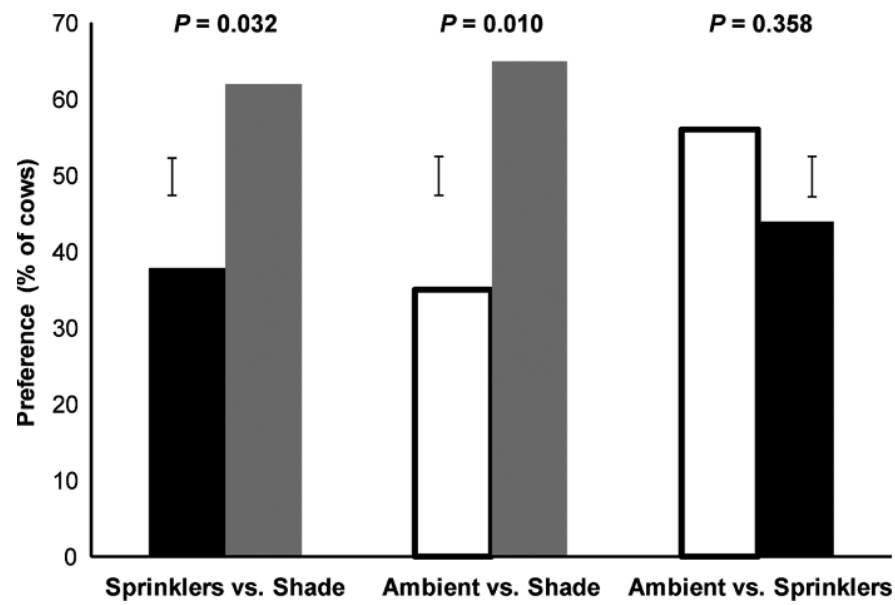

Figure 2. Preference ( \pm standard error of the difference) for shade (gray bars), sprinklers (black bars), or ambient conditions (open bars) of Holstein-Friesian dairy cows standing in shade, sprinklers, or in ambient conditions for $10 \mathrm{~min}$ in summer $(\mathrm{n}=96)$.

Similarly, body temperature increased more in cows that walked $2.0 \mathrm{~km}(0.9$ and $0.2 \%$ increase for the 2.0 $\mathrm{km}$ and $0.3 \mathrm{~km}$ walk, respectively; SED: $0.06 \%, P<$ 0.001). Surface temperature did not differ with distance walked $\left(2.0 \mathrm{~km}: 33.6^{\circ} \mathrm{C}\right.$; $0.3 \mathrm{~km}: 33.1^{\circ} \mathrm{C}$; SED: $0.40^{\circ} \mathrm{C}, P$ $=0.214)$. Regardless of distance, surface temperature was higher after the walk in cows with a greater percentage of black coat color $\left(0.027^{\circ} \mathrm{C}\right.$ per $1 \%$ increase in black color; SE: $\left.0.010^{\circ} \mathrm{C}, P=0.015\right)$. Similarly, surface temperature increased with solar radiation $\left(0.0041^{\circ} \mathrm{C}\right.$ per $100 \mathrm{~W} / \mathrm{m}^{2}$ increase; $\left.\mathrm{SE}: 0.0017^{\circ} \mathrm{C}, P=0.007\right)$.

\section{Behavior}

Sixty-two percent of the cows chose shade instead of sprinklers (SE: $5.0 \%, P=0.032$; Figure 2) and $65 \%$ chose shade instead of ambient conditions (SE: 5.1\%, $P=0.010$; Figure 2). Cows showed no preference between sprinklers and ambient conditions $(44 \%$ of the cows chose sprinklers; SE: $5.3 \%, P=0.358$; Figure 2). Weather conditions influenced the preference for shade compared with that for the other treatments. The preference for shade over ambient conditions increased with air temperature $\left(12 \%\right.$ increase per $1^{\circ} \mathrm{C}$ increase in temperature; SE: $5.6 \%, P=0.038$; Figure 3), solar radiation $\left(8 \%\right.$ increase per $100 \mathrm{~W} / \mathrm{m}^{2}$ increase; SE: $3.3 \%$, $P=0.012$ ), and wind speed (4\% increase per $1 \mathrm{~km} / \mathrm{h}$ increase; SE: $1.6 \%, P=0.006)$. No effect of $T H I$ or $H L I$ on this preference $(P \geq 0.132)$ was found. Similarly, the preference for shade over sprinklers increased with air temperature $\left(12 \%\right.$ increase per $1^{\circ} \mathrm{C}$ increase in temperature; SE: $5.4 \%, P=0.026$; Figure 3), solar radiation $\left(7 \%\right.$ increase per $100 \mathrm{~W} / \mathrm{m}^{2}$ increase; SE: $3.3 \%$, $P=0.030)$, and wind speed ( $3 \%$ increase per $1 \mathrm{~km} / \mathrm{h}$ increase; SE: $1.3 \%, P=0.026)$. However, the preference for shade over sprinklers decreased with humidity ( $1.5 \%$ decrease per $1 \%$ increase in humidity; SE: $0.7 \%$, $P=0.027)$. Again, no effect of THI or HLI on this choice $(P \geq 0.199)$ was found. Walking distance $(P \geq$ $0.396)$, body weight $(P \geq 0.052)$, milk production $(P \geq$ $0.139)$, and coat color $(P \geq 0.140)$ did not influence the preference for shade or sprinklers.

In general, cows showed fewer insect avoidance behaviors (tail flicks, hoof stamps, and head throws) when they used the sprinklers (Figure 4). However, the number of skin twitches increased when the cows used the sprinklers (Figure 4). Walking distance did not affect any insect avoidance behaviors $(P \geq 0.616)$. In contrast, the number of tail flicks increased with $H L I(0.8 \%$ increase per unit of $H L I$; SE: $0.19 \%, P<0.001)$ and number of skin twitches increased with air temperature (5.6\% increase per $1{ }^{\circ} \mathrm{C}$; SE: $\left.2.66 \%, P=0.040\right)$ and $H L I$ (1.3\% increase per unit of HLI; SE: $0.33 \%, P<0.001$ ). The number of hoof stamps increased with solar radiation $\left(4 \%\right.$ increase per $100 \mathrm{~W} / \mathrm{m}^{2}$ increase; SE: $1.7 \%, P=$ 0.085). A positive relationship between coat color and insect avoidance behavior was noted. Cows that had a greater percentage of black coat color performed more skin twitching ( $4.3 \%$ increase per $10 \%$ increase in black coat color; SE: $1.57 \%, P=0.008)$ and hoof stamping $(4.4 \%$ increase per $10 \%$ increase in black coat color; SE: $2.37 \%, P=0.069)$.

Cows changed their head position when they chose sprinklers. They spent more time with their heads lowered $(23,11$, and $13 \%$ for sprinklers, shade, and ambient, respectively; SED: $2.6 \%, P=0.009)$ and with their heads outside the wooden structure $(66,14$, and $32 \%$ for sprinklers, shade, and ambient, respectively; SED: $12.9 \%, P=0.003)$.

\section{Physiology}

Respiration rate was decreased most by sprinklers (38\% decrease) but also declined in shade and ambient conditions (17 and 13\% decrease, respectively; SED: $4.7 \%, P<0.001$; Table 2). The decrease in respiration rate was influenced by distance walked $(2.0 \mathrm{~km}: 27 \%$; $0.3 \mathrm{~km}: 18 \%$; SED: $4.1 \%, P=0.001)$. No effect of coat color $(P=0.725)$ or any interaction between distance walked and treatment choice $(P=0.650)$ was found.

Irrespective of which treatment cows chose, body temperature decreased during the $10 \mathrm{~min}$ of testing (Table 2); however, it decreased more in the cows that walked $2.0 \mathrm{~km}$ to the test arena than in those that walked $0.3 \mathrm{~km}\left(0.07\right.$ and $0.01^{\circ} \mathrm{C}$ decrease for the 2.0 $\mathrm{km}$ and $0.3 \mathrm{~km}$ walk, respectively; SED: $0.015^{\circ} \mathrm{C}, P=$ 0.001). Otherwise, the body temperature decreased to the same extent regardless of treatment $\left(\mathrm{SED}: 0.018^{\circ} \mathrm{C}\right.$, 


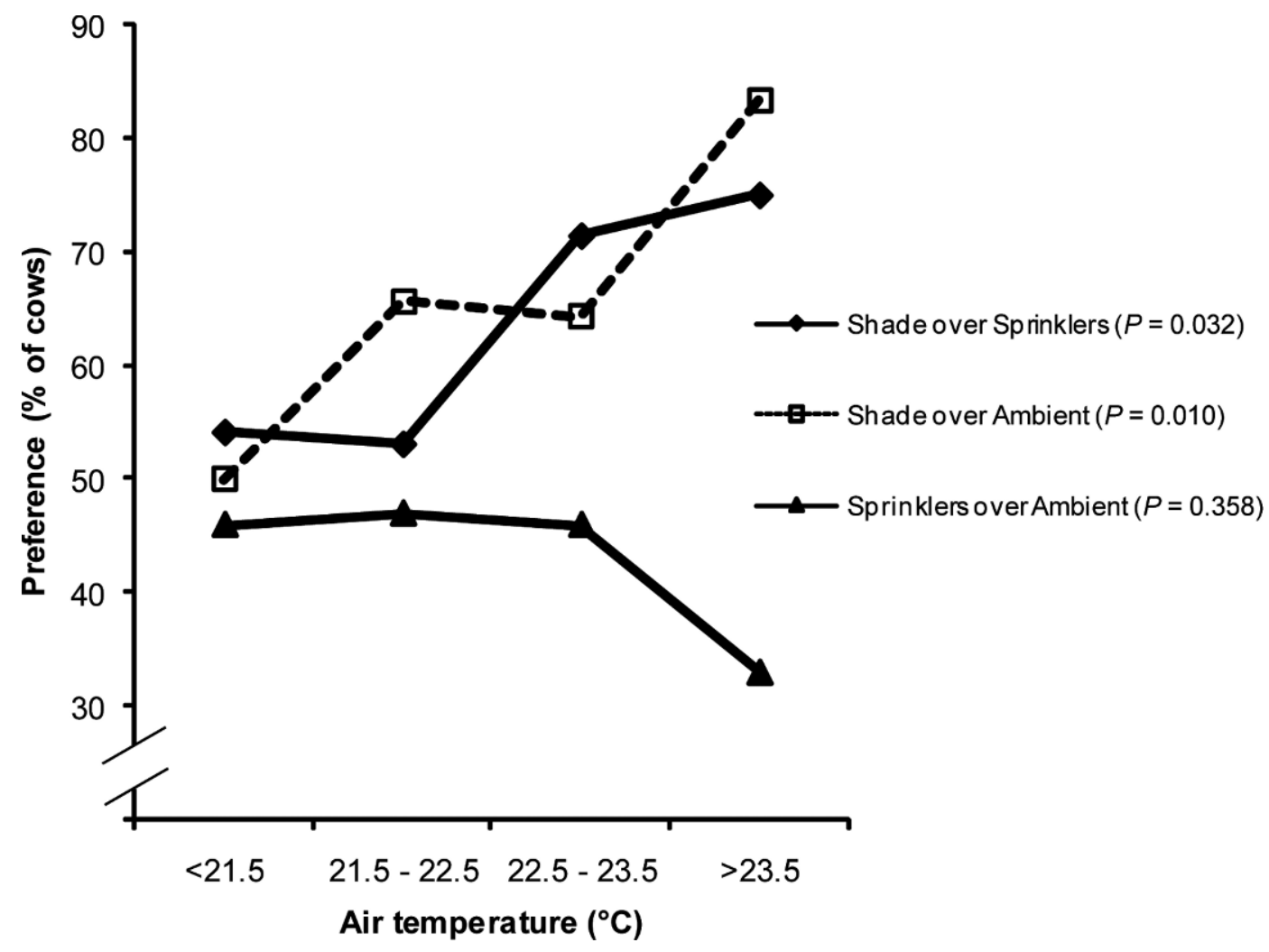

Figure 3. Relationship between the preference and air temperature of Holstein-Friesian dairy cows standing in shade, sprinklers, or in ambient conditions for $10 \mathrm{~min}$ in summer $(\mathrm{n}=96)$.

$P=0.194)$. The average body temperature during the 10 min of testing was 38.8 and $38.7^{\circ} \mathrm{C}$ for the cows that walked $2.0 \mathrm{~km}$ and $0.3 \mathrm{~km}$, respectively $\left(\mathrm{SED}: 0.07^{\circ} \mathrm{C}\right.$, $P=0.048)$. The cows that chose the sprinklers had a greater decrease in body temperature in warm weather $\left(0.008,0.001\right.$, and $0.0001^{\circ} \mathrm{C}$ decrease per unit increase in $H L I$ for sprinklers, shade and ambient, respectively; SED: $0.0024^{\circ} \mathrm{C}, P=0.004$, Figure 5).

After $10 \mathrm{~min}$ in the chosen treatment, the surface temperature was decreased to the greatest extent by sprinklers ( $11.4 \%$ decrease), compared with that by shade $(1.0 \%$ decrease) and ambient conditions $(1.4 \%$ increase; SED: $1.82 \%, P<0.001$; Table 2). Irrespective of treatment, the decrease in surface temperature was greater for animals that had walked $2.0 \mathrm{~km}$ compared with that for animals that only walked $0.3 \mathrm{~km}(5.4$ and $1.9 \%$ decrease, respectively; SED: $1.47 \%, P=0.029$ ). No interaction existed between weather conditions (air temperature, solar radiation, THI or HLI), treatment choice, and distance walked on the change in surface temperature $(P \geq 0.836)$.

We measured the differences in surface temperature between black and white coat color after the walk and after 10 min of testing using an IR thermometer pointed to either a black or white spot on the cow. Black coats were always warmer than white coats; surface temperatures after the walk were 33.6 and $31.5^{\circ} \mathrm{C}$, for black and white coat color, respectively (SED: $0.58^{\circ} \mathrm{C}, P<0.001$ ). Surface temperatures after the $10 \mathrm{~min}$ in the chosen treatments were still higher on black surfaces: 32.2 and $30.5^{\circ} \mathrm{C}$, for black and white coat color, respectively (SED: $0.68^{\circ} \mathrm{C}, P=0.012$ ).

\section{DISCUSSION}

Cows that chose to use sprinklers were cooler and showed fewer insect avoidance behaviors. Despite these advantages, cows preferred shade over sprinklers and ambient conditions (no cooling). Increased internal heat load, created by walking animals 2.0 versus $0.3 \mathrm{~km}$, did not change these choices, although the preference for shade did increase with ambient temperature.

Sixty-two percent of the cows chose shade over sprinklers and $65 \%$ chose shade over ambient conditions. These results agree with those from previous studies that have found that cattle will readily seek shade and this behavioral response increases in warm weather (Tucker et al., 2008; Schütz et al., 2009). Indeed, in the current experiment the preference for shade increased with ambient temperature by $12 \%$ for every $1{ }^{\circ} \mathrm{C}$. The 
Table 2. Respiration rate, surface temperature, and body temperature of Holstein-Friesian dairy cows before and after 10 min in sprinklers, shade, or in ambient conditions $(\mathrm{n}=96)$

\begin{tabular}{lccc}
\hline $\begin{array}{l}\text { Physiological } \\
\text { parameter }\end{array}$ & Sprinklers & Shade & Ambient \\
\hline Respiration rate (breaths/min) & & & \\
Before & 63 & 65 & 63 \\
After & 39 & 54 & 55 \\
Change & -24 & -11 & -8 \\
SED 1 & 2.1 & 2.1 & 2.1 \\
$P$-value & $<0.001$ & $<0.001$ & $<0.001$ \\
Surface temperature $\left({ }^{\circ} \mathrm{C}\right)$ & & & \\
Before & 33.4 & 33.5 & 33.2 \\
After & 29.6 & 33.1 & 33.6 \\
Change & -3.8 & -0.3 & 0.5 \\
SED & 0.43 & 0.43 & 0.43 \\
$P$-value & $<0.001$ & 0.420 & 0.295 \\
Body temperature $\left({ }^{\circ} \mathrm{C}\right)$ & & & \\
Before & 38.78 & 38.72 & 38.76 \\
After & 38.76 & 38.66 & 38.74 \\
Change & -0.028 & -0.060 & -0.028 \\
SED & 0.013 & 0.013 & 0.013 \\
$P$-value & 0.034 & $<0.001$ & 0.030 \\
\hline
\end{tabular}

${ }^{1}$ Standard error of the difference for the change within treatment.

${ }^{2} P$-value for the change within treatment compared with zero.

preference for shade also increased with increasing wind speed and decreased with humidity, which agrees with other results from the literature, suggesting that air movement underneath the shade is an important feature of shade to be an attractive resource to cattle (Buffing- ton et al., 1983). The cattle used in this experiment had considerable experience seeking shade, as trees are common throughout the farm. In contrast, whereas all of these cattle had experience with water cooling, they had not previously had control over this resource; the

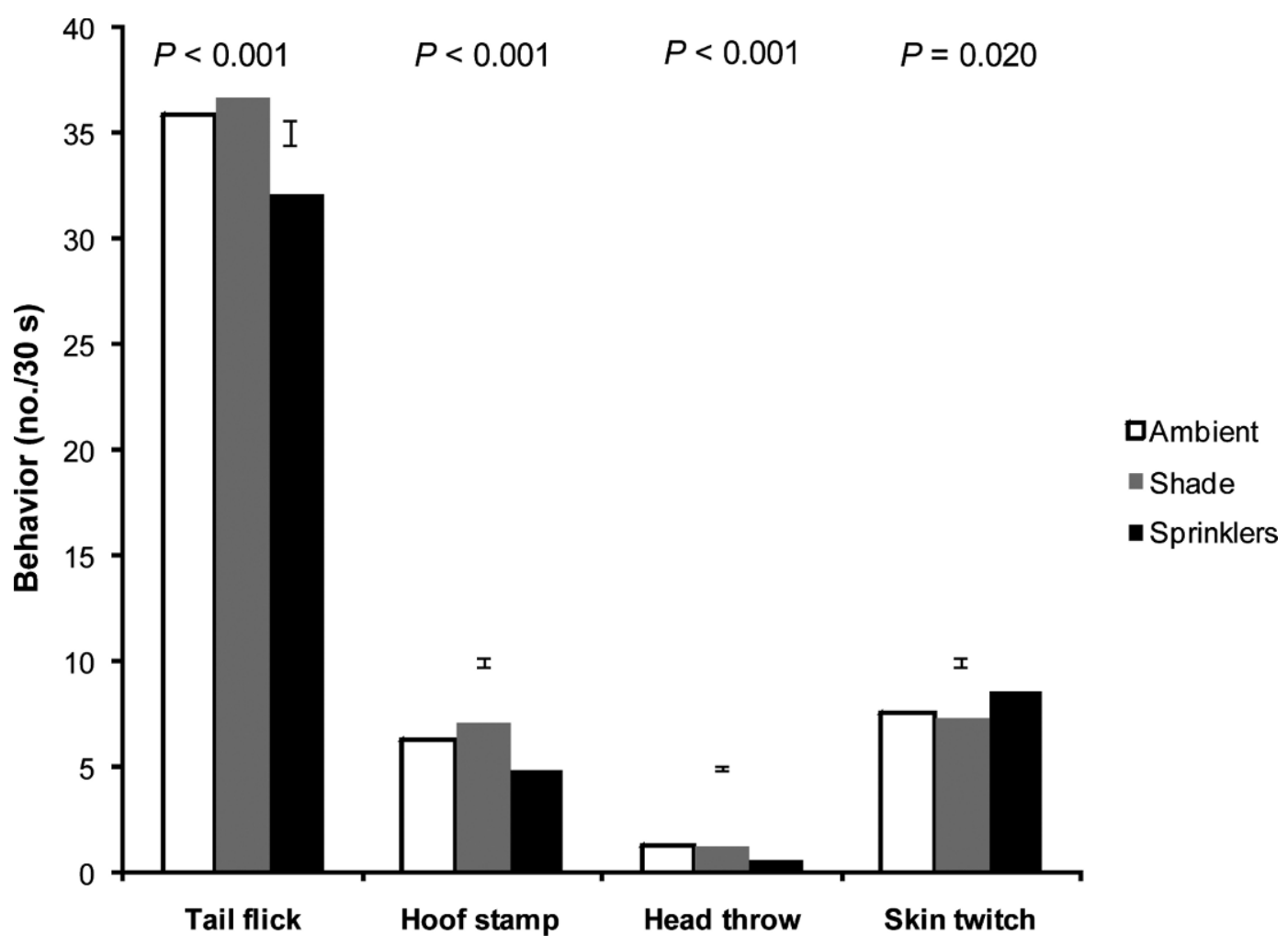

Figure 4. Insect avoidance behaviors (back-transformed means \pm standard error of the difference) of Holstein-Friesian dairy cows standing in shade, sprinklers, or in ambient conditions for $10 \mathrm{~min}$ in summer $(\mathrm{n}=96)$. 

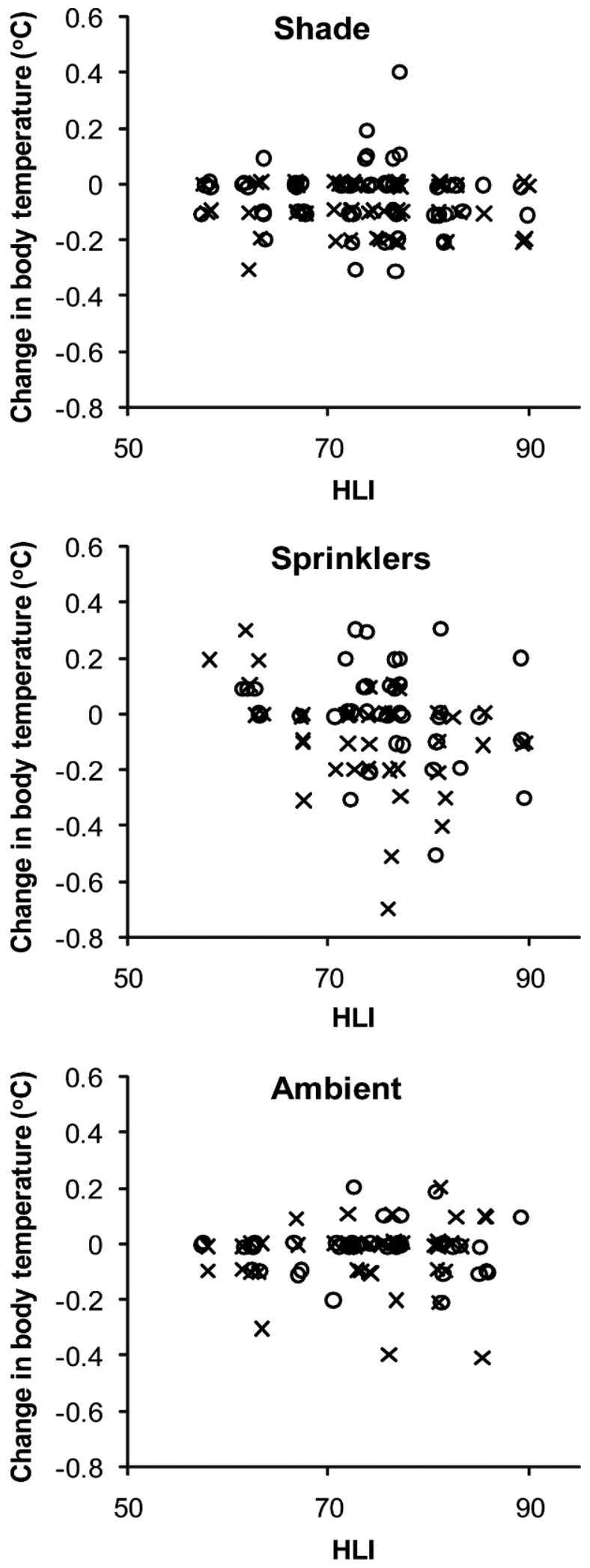

Figure 5. Relationship between change in body temperature and heat load index (HLI) in Holstein-Friesian dairy cows standing in shade, sprinklers, or in ambient conditions for $10 \mathrm{~min}$ in summer $(\mathrm{n}=$ 96) after a $0.3-\mathrm{km}(\mathrm{x})$ or $2.0-\mathrm{km}(\mathrm{o})$ walk. entire pen is usually involuntarily sprinkled while the cows wait for milking. It is unclear what effect this element of control has on the response. Other studies have shown that cattle voluntarily use sprinklers in very warm weather $\left(>32^{\circ} \mathrm{C}\right.$, Seath and Miller, 1948; > $27^{\circ} \mathrm{C}$, Igono et al., 1987); however, in these studies the animals did not have a choice between shade and sprinklers, nor did they quantify the amount of time spent in the water. More recently, we have found that nonlactating dairy cows will use an unshaded cow shower (2 large shower heads activated with pressure-sensitive floor) for, on average, $3 \mathrm{~h} / \mathrm{d}$ (Legrand et al., submitted). These results indicate that water may be heavily used in specific situations. Cows showed no preference between sprinklers and ambient conditions (44\% of the cows chose sprinklers). The differences between the study by Legrand and coworkers (submitted) and the present study are numerous. We speculate that the previous experience and degree of control over the resource may be 2 of the factors that influence the choice to use water for cooling. Indeed, it has been suggested by others that it may take a while for cattle to get used to being sprinkled (Mader et al., 2007).

We have found that voluntary use of a cow shower increases with heat load $\left(0.3 \mathrm{~h}\right.$ for every $1^{\circ} \mathrm{C}$ increase in temperature; Legrand et al., submitted ), but in the current study, the opposite was true. The preference for shade over sprinklers became more marked as ambient temperatures increased. In addition, cows that chose sprinklers spent more time standing with their heads lowered and with their heads outside the structure compared with when they were in shade or ambient conditions. Kendall et al. (2007) suggested that cows that were unable to escape wetting by sprinklers spent more time with the head in a lower position in an attempt to avoid getting water in sensitive areas like the ears, in part because this is the only part of the body they could readily move away from the water. Our results confirm that the cows indeed seemed to keep their heads away from the sprinklers. Contrary to this finding, Legrand et al. (submitted) demonstrated that cows spent approximately $50 \%$ of their time in a cow shower with their heads under or near the water source. The differences between these studies may be explained, in part, by the way the water cooling was provided. There is little research about what type of water cooling is preferred by cattle in terms of droplet sizes, flow rate, and water temperature or pressure, and these factors may play an important role in how cows respond to sprinklers.

Contrary to our predictions, the preference for shade over sprinklers did not change in favor for sprinklers when the heat load increased after walking a longer distance before testing, or in warm weather. In addi- 
tion, individual characteristics did not influence the choice. Animals are likely to differ in their susceptibility to warm weather due to differences in individual heat production. High-producing animals produce more heat (Kadzere et al., 2002) and are, thus, more likely to be susceptible to heat stress. There is also considerable evidence that cattle with a darker coat color are more sensitive to heat stress (Finch et al., 1984; Brown-Brandl et al., 2006) and seek shade more frequently compared with lighter colored animals (Gaughan et al., 1998). We expected animals that were heavier, produced more milk, and had dark coat colors to show a preference for more efficient cooling. However, this was not the case. Individual cow characteristics, such as body weight, milk production, and coat color did not influence any preference, and the reasons for this are unclear. It is possible that the low individual variation in coat color (most animals were dark, $82 \pm 20 \%$ black coat color, mean $\pm \mathrm{SD})$, body weight $(486 \pm 61 \mathrm{~kg}$, mean $\pm \mathrm{SD})$, and milk production $(12.7 \pm 3.48 \mathrm{~kg} / \mathrm{d}$, mean $\pm \mathrm{SD})$ contributed to this lack of preference.

The sprinklers were more efficient in reducing the heat load than shade; respiration rate was decreased by 38 and $17 \%$, and surface temperature by 11 and $1 \%$ for sprinklers and shade, respectively. The body temperature decreased in all treatments during the $10 \mathrm{~min}$ of testing, likely because all cows had stopped walking. Physical activity is known to rapidly increase the body temperature of cattle (increase in body temperature of 0.3 to $0.8^{\circ} \mathrm{C}$; Mader et al., 2005), regardless of distance walked, in agreement with the current findings. Cows that chose sprinklers had a greater reduction in body temperature in warm weather. The marked, rapid decline in respiration rate when cows used sprinklers agrees with other studies showing that water is more efficient than shade in reducing respiration rate (e.g., $62 \%$ reduction compared with a $30 \%$ reduction when only shade was provided) and body temperature (2 to $4 \mathrm{~h}$ after a 90 -min exposure, shade: $38.9^{\circ} \mathrm{C}$, sprinklers: $38.7^{\circ} \mathrm{C}$; Kendall et al., 2007).

The behavioral response differed between treatments. Cows that chose sprinklers showed fewer insect avoidance behaviors compared with cows that chose shade or ambient conditions, indicating that the sprinklers were more efficient in reducing insect load. These results are in accordance with findings of Kendall et al. (2007), which demonstrated that cows that were sprinkled with water performed half as many tail flicks and hoof stamps as cows in shade and control treatments. In the current study, insect avoidance behavior increased in warm weather and tail flicks were the most common behavior, followed by skin twitches, hoof stamps, and head throws. Previous research has shown that insect avoidance behaviors, such as skin twitches, stamp/ kicks, and head, tail, and ear movements increase with fly load (Vitela et al., 2007). Cows performed more skin twitches when using the sprinklers, but this may have been due to water droplets hitting the skin. A positive relationship also existed between coat color and insect avoidance behavior. Cows that had a greater percentage of black coat color performed more hoof stamps and skin twitches. Dark colors absorb more heat (Finch et al., 1984) and dark coat colors are warmer compared with lighter colors. We speculate that the higher surface temperature on dark colored cattle possibly attracted more flies.

In conclusion, dairy cows preferred to use shade over sprinklers and ambient conditions (no cooling) after walking 0.3 and $2.0 \mathrm{~km}$. The preference for shade increased in warm weather, despite the finding that sprinklers were more efficient in reducing the heat load and insect avoidance behavior. Further work investigating preferences for specific design features of water cooling, such as droplet size and impact, and the role of previous experience and control over delivery is needed to best deliver water cooling to dairy cattle.

\section{ACKNOWLEDGMENTS}

We gratefully acknowledge the technical assistance from all observers and AgResearch staff: Sarah Adams, Gonzalo Caracelas, Jimmy and Dick Coventry, Daina Harris, Michelle Hawke, Frankie Huddart, Kevin Orr, Moana Puha, Haley Shepherd, and Gemma Worth. We are also grateful to the staff at AgResearch No.1 dairy. This work was funded by DairyNZ (Hamilton, New Zealand) and by the Foundation for Research, Science, and Technology (Wellington, New Zealand).

\section{REFERENCES}

Armstrong, D. V. 1994. Heat stress interaction with shade and cooling. J. Dairy Sci. 77:2044-2050.

Brown-Brandl, T. M., R. A. Eigenberg, and J. A. Nienaber. 2006. Heat stress risk factors of feedlot heifers. Livest. Sci. 105:57-68.

Buffington, D. E., R. J. Collier, and G. H. Canton. 1983. Shade management systems to reduce heat stress for dairy cows in hot, humid climates. Trans. ASABE 26:1798-1802.

Correa-Calderon, A., D. Armstrong, D. Ray, S. de Nise, M. Enns, and C. Howison. 2004. Thermoregulatory responses of Holstein and Brown Swiss heat stressed dairy cows to two different cooling systems. Int. J. Biometeorol. 48:142-148.

De Rensis, F., and R. J. Scaramuzzi. 2003. Heat stress and seasonal effects on reproduction in the dairy cow-A review. Theriogenology 60:1139-1151.

Finch, V. A., I. L. Bennett, and C. R. Holmes. 1984. Coat colour in cattle: effect on thermal balance, behavior and growth, and relationship with coat type. J. Agric. Sci. 102:141-147.

Gaughan, J. B., P. J. Goodwin, T. A. Schoorl, B. A. Young, M. Imbeah, T. L. Mader, and A. Hall. 1998. Shade preferences of lactating Holstein-Friesian cows. Aust. J. Exp. Agric. 38:17-21.

Gaughan, J. B., T. L. Mader, S. M. Holt, and A. Lisle. 2008. A new heat load index for feedlot cattle. J. Anim. Sci. 86:226-234. 
Hahn, G. L. 1999. Dynamic responses of cattle to thermal heat loads. J. Anim. Sci. 77:10-20.

Igono, M. O., G. Bjotvedt, and H. T. Sanford-Crane. 1992. Environmental profile and critical temperature effects on milk production of Holstein cows in desert climate. Int. J. Biometeorol. 36:7787.

Igono, M. O., H. D. Johnson, B. J. Steevens, G. F. Krause, and M. D. Shanklin. 1987. Physiological, productive, and economic benefits of shade, spray, and fan system versus shade for Holstein cows during summer heat. J. Dairy Sci. 70:1069-1079.

Kadzere, C. T., M. R. Murphy, N. Silankove, and E. Maltz. 2002. Heat stress in lactating dairy cows: A review. Livest. Prod. Sci. 77:59-91.

Kendall, P. E., P. P. Nielsen, J. R. Webster, G. A. Verkerk, R. P. Littlejohn, and L. R. Matthews. 2006. The effects of providing shade to lactating dairy cows in a temperate climate. Livest. Sci. 103:148-157.

Kendall, P. E., G. A. Verkerk, J. R. Webster, and C. B. Tucker. 2007. Sprinklers and shade cool cows and reduce insect-avoidance behavior in pasture-based dairy systems. J. Dairy Sci. 90:3671-3680.

Legrand, A., K. E. Schütz, and C. B. Tucker. In press. Using water to cool cattle: Behavioral and physiological changes associated with voluntary use of cow showers. J. Dairy Sci. 10.3168/jds.20103901.

Mader, T. L., M. S. Davis, and J. B. Gaughan. 2007. Effect of sprinkling on feedlot microclimate and cattle behavior. Int. J. Biometeorol. 51:541-551.

Mader, T. L., M. S. Davis, and W. M. Kreikmeier. 2005. Case study: Tympanic temperature and behavior associated with moving feedlot cattle. Prof. Anim. Sci. 21:339-344.

Marcillac-Embertson, N. M., P. H. Robinson, J. G. Fadel, and F. M Mitloehner. 2009. Effects of shade and sprinklers on performance, behavior, physiology, and the environment of heifers. J. Dairy Sci. 92:506-517.

Martin, P., and P. Bateson. 1993. Measuring Behavior. An Introductory Guide. 2nd edition. Cambridge University Press, Cambridge, UK.

Mitlöhner, F. M., J. L. Morrow, J. W. Dailey, S. C. Wilson, M. L. Galyean, M. F. Miller, and J. J. McGlone. 2001. Shade and water misting effects on behavior, physiology, performance, and carcass traits of heat-stressed feedlot cattle. J. Anim. Sci. 79:2327-2335.
Ominski, K. H., A. D. Kennedy, K. M. Wittenberg, and S. A. Moshtaghi Nia. 2002. Physiological and production responses to feeding schedule in lactating dairy cows exposed to short-term, moderate heat stress. J. Dairy Sci. 85:730-737.

Roche, J. R., P. G. Dillon, C. R. Stockdale, L. H. Baumgard, and M. J. VanBaale. 2004. Relationships among international body condition scoring systems. J. Dairy Sci. 87:3076-3079.

Roman-Ponce, H., W. W. Thatcher, D. E. Buffington, C. J. Wilcox, and H. H. Van Horn. 1977. Physiological and production responses of dairy cattle to a shade structure in a subtropical environment. J. Dairy Sci. 60:424-430.

Schütz, K. E., N. R. Cox, and L. R. Matthews. 2008. How important is shade to dairy cattle? Choice between shade or lying following different levels of lying deprivation. Appl. Anim. Behav. Sci. 114:307-318.

Schütz, K. E., A. R. Rogers, N. R. Cox, and C. B. Tucker. 2009. Dairy cows prefer shade that offers greater protection against solar radiation in summer: Shade use, behavior, and body temperature. Appl. Anim. Behav. Sci. 116:28-34.

Schütz, K. E., A. R. Rogers, Y. A. Poulouin, N. R. Cox, and C. B. Tucker. 2010. The amount of shade influences the behavior and physiology of dairy cattle. J. Dairy Sci. 93:125-133.

Seath, D. M., and G. D. Miller. 1948. Effect of water sprinkling with and without air movement on cooling dairy cows. J. Dairy Sci. 31:361-366.

Tucker, C. B., A. R. Rogers, and K. E. Schütz. 2008. Effect of solar radiation on dairy cattle behaviour, use of shade and body temperature in a pasture-based system. Appl. Anim. Behav. Sci. 109:141-154.

Tucker, C. B., G. A. Verkerk, B. H. Small, I. S. Tarbotton, and J. R. Webster. 2005. Animal welfare in large dairy herds: A survey of current practices. Proc. N.Z. Soc. Anim. Prod. 65:127-131.

Valtorta, S. E., P. E. Leva, and M. R. Gallardo. 1997. Evaluation of different shades to improve dairy cattle well-being in Argentina. Int. J. Biometeorol. 41:65-67.

Vitela, M. I., C. Cruz-Vázquez, J. J. Solano, and A. Orihuela. 2007. A note on the associations between the prevalence of stable flies (Stomoxys calcitrans) and the behaviour of dairy cows under semiarid conditions. J. Anim. Vet. Adv. 6:1284-1290.

West, J. W. 2003. Effects of heat-stress on production in dairy cattle. J. Dairy Sci. 86:2131-2144. 